In der Rubrik „Literatur kompakt" werden die wichtigsten Originalarbeiten aus der internationalen Fachliteratur referiert.

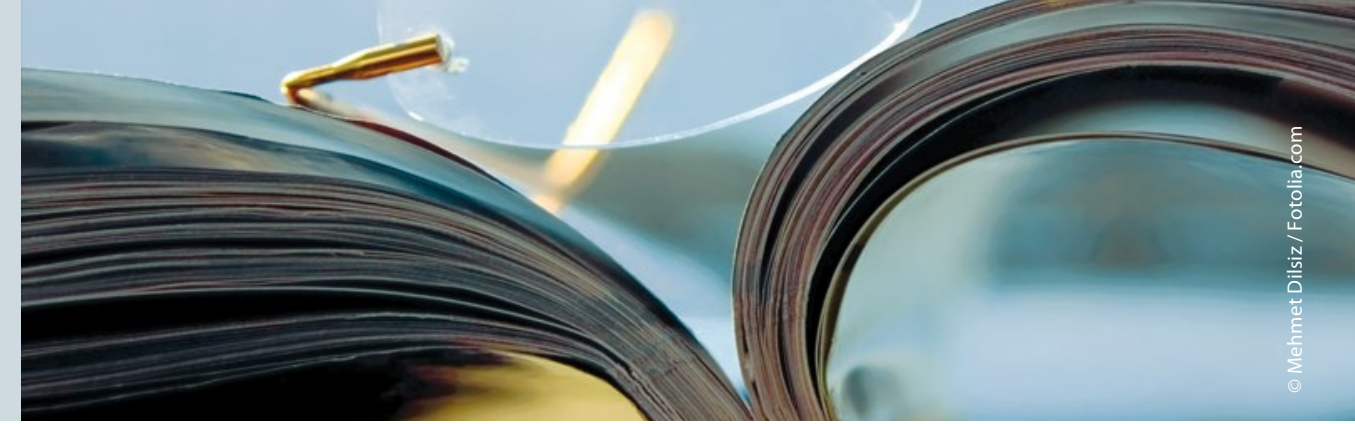

\section{Keuchhusten: Impfung Schwangerer schützt Kinder im ersten Lebensjahr}

\section{Werden Schwangere gegen Keuchhusten geimpft, schützt das die Kinder bis zum Ende des ersten Lebensjahres.}

$\mathrm{D}$ ie Erstimpfung gegen Keuchhusten erfolgt in den USA mit einem Kombinationsimpfstoff DTaP, also gleichzeitig gegen Diphtherie und Tetanus und mit einer azellulären Pertussis-Vakzine. Empfohlen wird die Impfung für Kinder im Alter von zwei, vier und sechs Monaten. Ohne die Impfung gegen Keuchhusten nimmt der durch die Antikörper (Ak) der Mutter dargebotene Schutz im Laufe der ersten sechs Lebenswochen kontinuierlich ab, bis nach vier Monaten keine schützenden Ak der Mutter mehr nachweisbar sind. Auch wurde festgestellt, dass Neugeborene von Müttern, die in der Schwangerschaft mit einer Tdap-Vakzine (reduziertes DiphtherieToxoid und azelluläres Pertussis-Antigen in niedriger Dosierung) geimpft wurden, einen höheren Ak-Titer gegen den Keuchhustenerreger haben, bevor sie die erste DTaP-Impfdosis erhalten.

In einer von dem US-Versicherer Kaiser Permanente unterstützten Studie wurde nun geprüft, wie gut die Impfung von Schwangeren einen Keuchhusten bei Kindern innerhalb der ersten beiden Lebensmonate und des ersten Lebensjahres verhindert. Darüber hinaus wurde in der Studie die Effektivität der Impfung von Schwangeren nach der Dreifachimpfung der Kinder mit einer DTaP-Vakzine bestimmt, denn es gab Hinweise über negative Wechselwirkungen.
In die Studie wurden fast 150.000 Neugeborene eingeschlossen, die zwischen 2010 - dem Jahr, in dem die Schwangerenimpfung erstmals empfohlen wurde - und 2015 in den 21 Kliniken von Kaiser Permanente in Kalifornien zur Welt kamen. Die teilnehmenden Mütter mussten vor 1996 geboren sein, um sicherzustellen, dass sie zur Grundimmunisierung gegen Keuchhusten die Ganzkeim-Vakzine erhalten hatten. Die meisten Schwangeren wurden mindestens acht Tage vor der Geburt geimpft. Der Nachweis einer Pertussis-Infektion bei Kindern erfolgte mithilfe der Polymerasekettenreaktion (PCR).

Roger Paul Baxter, Internist und Kodirektor des Kaiser Permanente Vaccine Study Center in Oakland, und seine Kollegen ermittelten innerhalb der ersten zwei Lebensmonate eine Wirksamkeit der Impfung von Schwangeren mit der Tdap-Vakzine von 91,4\%. Im Zeitraum zwischen Geburt und Ende des ersten Lebensjahres lag sie bei $69,0 \%$. Und selbst nach Impfung der Neugeborenen gab es Hinweise auf einen zusätzlichen Nutzen der Impfung der Schwangeren.

Der Auswertung zufolge lag die Wirksamkeit der Impfung bei noch ungeimpften Neugeborenen bei 87,9\%. Zwischen der ersten und zweiten DTaPImpfstoffdosis für die Neugeborenen betrug die Wirksamkeit $81,4 \%$, zwi- schen der zweiten und dritten Dosis $6,4 \%$ und nach allen drei Impfungen $65,9 \%$. Dieses Studienergebnis entspreche denen zweier Studien in Großbritannien und stütze die derzeitige Empfehlung in Kalifornien, Schwangere mit der Tdap-Vakzine zu impfen, so die autoren. Die niedrige Impfeffizienz zwischen der zweiten und dritten Dosis erklären sie sich durch die wenigen Keuchhustenerkrankungen und den kurzen Zeitraum zwischen der Applikation der Impfdosen.

In Deutschland empfiehlt die STIKO die Impfung Schwangerer nicht explizit. In der aktuellen Empfehlung heißt es für die Grundimmunisierung, sie bei Säuglingen und Kleinkindern „zum frühestmöglichen Zeitpunkt, das heißt unmittelbar nach Vollendung des 2. Lebensmonats, zu beginnen und sie zeitgerecht fortzuführen". Für Frauen gilt: „Erfolgte die Impfung nicht vor der Konzeption, sollte die Mutter bevorzugt in den ersten Tagen nach der Geburt des Kindes geimpft werden." Ein monovalenter Impfstoff gegen Pertussis existiert in Deutschland nicht, deshalb ist ein Kombinationsimpfstoff anzuwenden, und zwar im ersten Lebensjahr mit einem höheren Pertussis-Antigengehalt (aP).

Nach Angaben des Robert Koch-Instituts wird die STIKO „eine mögliche Empfehlung auf Basis der aus England und den USA zu erwartenden Studiendaten und Erfahrungen in naher $\mathrm{Zu}$ kunft diskutieren“.

Peter Leiner

Baxter R et al. Effectiveness of Vaccination During Pregnancy to Prevent Infant Pertussis. Pediatrics. 2017;139(5):e20164091 